\title{
Interaction between NifL and NifA in the nitrogen- fixing Pseudomonas stutzeri A1501
}

\author{
Correspondence \\ Min Lin \\ linmin57@vip.163.com
}

Received 29 May 2006

Revised 30 August 2006

Accepted 1 September 2006

\author{
Zhihong Xie, ${ }^{1} \dagger$ Yuetang Dou, ${ }^{1}$ Shuzheng Ping, ${ }^{1}$ Ming Chen, ${ }^{1}$ \\ Guoying Wang, ${ }^{2}$ Claudine Elmerich ${ }^{3} \ddagger$ and Min Lin ${ }^{1}$ \\ ${ }^{1}$ Biotechnology Research Institute, CAAS, Beijing, PR China \\ ${ }^{2}$ Biology College, China Agricultural University, Beijing, PR China \\ ${ }^{3}$ Institut des Sciences du Végétal, CNRS UPR-2355, Gif-sur-Yvette, France
}

\begin{abstract}
Pseudomonas stutzeri strain A1501 isolated from rice fixes nitrogen under microaerobic conditions in the free-living state. This paper describes the properties of nif $L$ and nif $A$ mutants as well as the physical interaction between NifL and NifA proteins. A nifL mutant strain that carried a mutation nonpolar on nifA expression retained nitrogenase activity. Complementation with a plasmid containing only nif $L$ led to a decrease in nitrogenase activity in both the wild-type and the nif $L$ mutant, suggesting that NifL acts as an antiactivator of NifA activity. Using the yeast two-hybrid system and purified protein domains of NifA and NifL, an interaction was shown between the $\mathrm{C}$-terminal domain of NifL and the central domain of NifA, suggesting that NifL antiactivator activity is mediated by direct protein interaction with NifA.
\end{abstract}

\section{INTRODUCTION}

Regulation of nitrogen fixation (nif) gene expression, in response to the environmental signals ammonium and $\mathrm{O}_{2}$, depends on the transcriptional activator, NifA, a member of the $\sigma^{54}$-dependent family of bacterial activators (Morett \& Segovia, 1993). The mode of activation of nif gene transcription by NifA appears to be common to a large number of diazotrophs, whereas the regulation of NifA synthesis and activity differs from one organism to another (Merrick, 2004). NifA activity in the gamma subgroup of proteobacteria is controlled by the antiactivator NifL. Indeed, NifA and NifL form an atypical two-component sensor-regulator system, and NifL modulates the activity of NifA by direct protein-protein interaction (MartínezArgudo et al., 2004). NifA proteins are structurally similar to each other. This enabled the description of NifA as a multidomain protein (Studholme \& Dixon, 2003 and references therein). The catalytic domain of NifA, which interacts with the RNA polymerase, shares a high degree of identity with an AAA + -type ATPase. The C-terminal part is the DNA-binding domain and contains an HTH motif. The $\mathrm{N}$-terminal domain carries a GAF domain. The NifL protein resembles histidine kinase protein (HPK), but NifL is not subject to autophosphorylation. The amino-terminal region

tPresent address: Department of Biochemistry, Cellular and Molecular Biology, the University of Tennessee, Knoxville, TN 37996, USA.

‡Present address: Département de Microbiologie, Biologie Moléculaire du Gène chez les Extrêmophiles, Institut Pasteur, 75724 Paris Cedex 15, France.

Abbreviation: GST, glutathione S-transferase. contains a PAS domain, and it has been proposed that this region may be involved in $\mathrm{O}_{2}$ sensing (Zhulin et al., 1997). The C-terminal region shows similarity to the GHKL superfamily of ATPases.

The nitrogen fixation ability within the genus Pseudomonas has been questioned for a long time (for reviews see Chan et al., 1994; Lalucat et al., 2006). It is now established that several strains of Pseudomonas stutzeri can fix nitrogen (Vermeiren et al., 1999; Rediers et al., 2004). P. stutzeri A1501, isolated from rice, fixes nitrogen in the free-living state, under microaerobic conditions in media devoid of ammonia (You et al., 1991; Lin et al., 2000; Desnoues et al., 2003). A $30 \mathrm{~kb}$ DNA region containing the nitrogen fixation ( $n i f$ and $r n f$ ) genes has been previously characterized and the regulatory nifLA region mapped within the main nif cluster. By using different lac Z fusions, it was observed that nifA controlled the expression of other nif (and $r n f$ ) operons and that chromosomal nifLA-lacZ fusion expression was strongly reduced in the presence of oxygen and ammonia (Desnoues et al., 2003). As NtrC and RpoN were also found to control nifLA expression (Desnoues et al., 2003), this suggested that the regulation circuitry in $P$. stutzeri resembled more the situation in Klebsiella pneumoniae than in Azotobacter species, where nifLA expression is not impaired in the presence of ammonia (Blanco et al., 1993), although $P$. stutzeri is phylogenetically closer to Azotobacter (Rediers et al., 2004) than to Klebsiella. The objective of this work was to further document the role of NifLA in P. stutzeri A1501. In particular, the properties of a nifL mutant strain non-polar on nifA expression as well as the physical interaction between NifL and NifA were investigated. 


\section{METHODS}

Strains and plasmids. Plasmids and bacterial strains are listed in Table 1. P. stutzeri was grown in minimal lactate medium or in LB medium at $30^{\circ} \mathrm{C}$ as described by Desnoues et al. (2003). The yeast strain used for the two-hybird analysis was Saccharomyces cerevisiae PJ69-4A harbouring three reporter genes, lacZ, ADE2 and HIS3, under the control of the GAL promoter (James et al., 1996). Yeast cells were grown in YPD rich medium or in SD minimal medium supplemented with appropriate amino acids, at $30^{\circ} \mathrm{C}$, as described in the manual supplied with the Matchmaker Two-Hybrid System (Clontech). Antibiotics were used at the following concentrations $\left(\mu \mathrm{g} \mathrm{ml}^{-1}\right)$ : ampicillin $(\mathrm{Amp}), 100$; kanamycin $(\mathrm{Km}), 50$; tetracycline (Tc), 10.

Nitrogenase activity. Nitrogenase activity was determined with bacterial suspensions incubated at an $\mathrm{OD}_{600}$ of $0 \cdot 1$, in $\mathrm{N}$-free minimal lactate medium, at $30{ }^{\circ} \mathrm{C}$, under an argon atmosphere containing $1 \%$ oxygen and $10 \%$ acetylene, according to the derepression protocol described by Desnoues et al. (2003). Nitrogenase specific activity is expressed as nmol ethylene $\min ^{-1}$ (mg protein $)^{-1}$. Protein concentrations were determined by the Bio-Rad protein assay (BSA protein standard). Each experiment was repeated at least three times.

Molecular techniques. Plasmid isolation, genomic DNA extraction, gel electrophoresis, restriction mapping, transformation and molecular cloning, Western blotting and amplification by PCR (Amersham kit) were performed by standard methods (Sambrook \&
Russell, 2001) or as recommended by the manufacturers of the products used. Restriction enzymes were purchased from Promega and oligonucleotides from Shanghai Biotech Company. Nucleotide sequencing was performed by the Takara Company.

RT-PCR. Total RNA was isolated by acid-phenol extraction and the single-stranded cDNA synthesis was performed using the ProtoScript First Strand cDNA Synthesis Kit (New England Biolabs). RNA $(1 \mu \mathrm{g})$ isolated from bacteria grown under nitrogen fixation conditions was used for RT-PCR to amplify a $415 \mathrm{bp}$ fragment with primers specific for nifA, RT-PCRnifAF and RT-PCRnifAR (Table 2). After 35 cycles of PCR amplification $\left(94^{\circ} \mathrm{C}\right.$ for $1 \mathrm{~min}$; $58^{\circ} \mathrm{C}$ for $1 \mathrm{~min} ; 72^{\circ} \mathrm{C}$ for $1 \mathrm{~min}$ ), PCR products were separated on $0 \cdot 8 \%$ agarose gels and visualized by ethidium bromide staining.

Construction of nifL mutants. Construction of strain 1507B, a nifL deletion non-polar mutant, was similar to strain 1507 previously described (Desnoues et al., 2003), except that it carries the KIXX cassette in the same orientation as the nifA gene. A nifL polar mutant, designated 1507A, was constructed for this work, as follows. Oligonucleotide primers pL-F and pL-R (see Table 2) were designed to amplify a $1647 \mathrm{bp} \mathrm{BamHI-HindIII} \mathrm{fragment} \mathrm{that} \mathrm{was} \mathrm{cloned} \mathrm{at}$ the unique BamHI-HindIII sites of the pSUP202 vector. Then, the KIXX cassette was inserted, as a SmaI fragment, into the unique ApaI site within the nifL coding sequence, previously treated with the Klenow fragment of DNA polymerase I to fill in ends. The orientation of the $\mathrm{Km}$ resistance gene was the opposite of that of the nifA gene. Plasmids were transferred into P. stutzeri recipients by conjugation, using Escherichia coli S17-1 as the donor, as previously

Table 1. Strains and plasmids

\begin{tabular}{|c|c|c|}
\hline Strain/plasmid & Relevant characteristics & Source/reference \\
\hline \multicolumn{3}{|l|}{ P. stutzeri } \\
\hline A1501 & Wild-type, Chinese Culture Collection: CGMCC 0351 & $\begin{array}{l}\text { Lin et al. (2000); } \\
\text { Desnoues et al. (2003) }\end{array}$ \\
\hline 1506 & nifA- $k m$ deletion mutant, Nif $\mathrm{Km}^{\mathrm{r}}$ & Desnoues et al. (2003) \\
\hline 1507B & nifL-km deletion mutant, non-polar on nifA expression, $\mathrm{Nif}^{+} \mathrm{Km}^{\mathrm{r}}$ & Nicole Desnoues \\
\hline $1507 \mathrm{~A}$ & nifL- $k m$ mutant, polar on nifA expression, Nif $\mathrm{Km}^{\mathrm{r}}$ & This study \\
\hline \multicolumn{3}{|l|}{ S. cerevisiae } \\
\hline PJ69-4A & $\begin{array}{l}\text { MATa trp1-109 leu2-3,112 ura3-52 his3-200 gal4s gal80 LYS2:: GAL1-HIS3 } \\
\text { GAL2-ADE2 met2:: GAL7-lacZ }\end{array}$ & James et al. (1996) \\
\hline \multicolumn{3}{|c|}{ 皮 } \\
\hline $\mathrm{pET}-28 \mathrm{a}(+)$ & $\begin{array}{l}\text { Cloning vector carrying a } \mathrm{His}_{6} \text { linker for expression and purification of } \\
\text { proteins, } \mathrm{Km}^{\mathrm{r}}\end{array}$ & Novagen \\
\hline pGAD-C ${ }_{1}^{*}$ & Expression vector for yeast two-hybrid system, GAL4(768-881), LEU2, Amp ${ }^{\mathrm{r}}$ & James et al. (1996) \\
\hline pGBD-C ${ }_{1}^{*}$ & Expression vector for yeast two-hybrid system, GAL4(1-147), TRP2, Amp ${ }^{\mathrm{r}}$ & James et al. (1996) \\
\hline pGAD-SIP and pBDU-SNF I & Positive control for yeast two-hybrid system, $\mathrm{Amp}^{\mathrm{r}}$ & James et al. (1996) \\
\hline pGEX-2T & Cloning vector which expresses GST protein, $\mathrm{Amp}^{\mathrm{r}}$ & Pharmacia \\
\hline pGST-NifLc & $\begin{array}{l}\text { pGEX-2T derivative carrying a } 1145 \mathrm{bp} \text { fragment encoding the C-terminal } \\
\text { portion of nifL, } \mathrm{Amp}^{\mathrm{r}}\end{array}$ & This study \\
\hline pHis $_{6}-\mathrm{NifA}$ & pET28a $(+)$ derivative carrying 1587 bp PCR product of nifA, $\mathrm{Km}^{\mathrm{r}}$ & This study \\
\hline pSUP202 & Suicide vehicle, $\mathrm{Ap}^{\mathrm{r}} \mathrm{Tc}^{\mathrm{r}} \mathrm{Cm}^{\mathrm{r}}$ & Simon et al. (1983) \\
\hline pUC4-KIXX & Source of $\mathrm{km}$ cassette & Pharmacia \\
\hline pVA1 & $\begin{array}{l}\text { pVK100 derivative carrying a nifA promoterless gene in opposite orientation } \\
\text { of the } \mathrm{km} \text { gene, } \mathrm{Tc}^{\mathrm{r}}\end{array}$ & This study \\
\hline pVA3 & As pVA1, but with nifA under the control of the $k m$ promoter, $\mathrm{Tc}^{\mathrm{r}}$ & This study \\
\hline pVK100 & RK2 replicon, $\mathrm{Tra}^{-} \mathrm{Km}^{\mathrm{r}} \mathrm{Tc}^{\mathrm{r}}$ & Allen \& Hanson (1985) \\
\hline $\mathrm{pVL}$ & pVK100 derivative carrying nifL & This study \\
\hline
\end{tabular}

${ }^{\star}$ For pGAD and pGBD derivatives containing entire or portions of nifA and nifL, constructed in this work, see Fig. 2, Table 2 and Table 3 . 
Table 2. Oligonucleotides primers

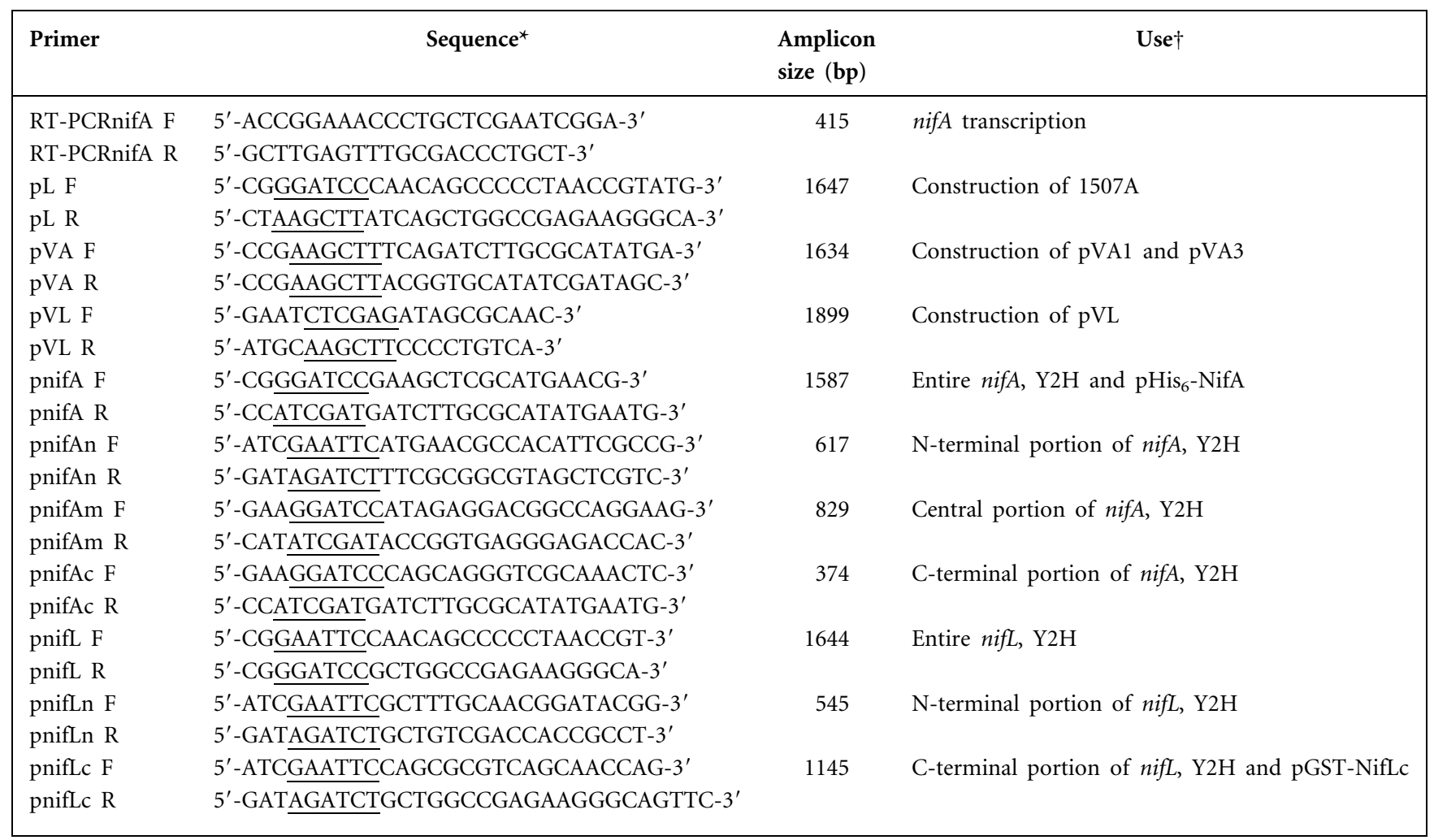

${ }^{\star}$ Restriction sites are underlined.

$\dagger \mathrm{Y} 2 \mathrm{H}$ : amplicons were cloned in pGAD and pGBD vectors for the yeast two-hybrid experiments; see Table 3 and Fig. 2.

described (Desnoues et al., 2003). Recombination in the host genome at the correct location was checked for by PCR amplification with appropriate oligonucleotide primers.

Construction of nifL- and nifA-containing plasmids. Oligonucleotides flanking the coding region of nifA and nifL were designed (see Table 2) to amplify the corresponding genes by PCR. For nifA, a 1634 bp promoterless DNA fragment was amplified and cloned as a HindIII fragment into the $\mathrm{Km}$ resistance gene of pVK100 under the control of the $\mathrm{km}$ promoter for pVA3 and in the opposite orientation for pVA1. For nifL, the amplified $1899 \mathrm{bp}$ fragment contained $239 \mathrm{bp}$ of the non-coding sequence; it was cloned as a HindIII-XhoI fragment into the Km resistance gene of pVK100 in the same orientation as the $\mathrm{Km}$ resistance gene, to yield pVL.

Yeast two-hybrid analysis. The oligonucleotides designed to amplify the fragments encoding the desired domains of NifA and NifL are listed in Table 2. PCR amplification of strain A1501 genomic DNA was performed with the Proof Start DNA polymerase (Qiagen) and the resulting amplicons were cloned in-frame into pGBD- $\mathrm{C}_{1}$ or $\mathrm{pGAD}-\mathrm{C}_{1}$ vectors (Table 1 ). The fusion junctions were verified in all the constructed plasmids by nucleotide sequence analyses. S. cerevisiae competent cells were prepared using the method described in the Matchmaker II protocol and pGAD and pGBD derivatives were co-transformed into the yeast recipient. The interaction between NifA and NifL domains was screened for by growth on SD medium lacking Leu, His, Trp and Ade (Table 3). The filter and quantitative liquid $\beta$-galactosidase assay were done according to the protocol described by the Matchmaker II system (Clontech). Activity is expressed as Miller units (Miller, 1972).
Expression and purification of NifL and NifA fusion proteins. A1501 nifA was amplified by PCR using oligonucleotides pnifA F and $\mathrm{R}$ (Table 2) and the amplicon was cloned into $\operatorname{pET} 28 \mathrm{a}(+)$ vector (Novagen) to generate a $\mathrm{His}_{6}$-tagged NifA fusion protein. Similarly, oligonucleotides pnifL-C, F and R were used to amplify the C-terminal portion of nifL, which was constructed to fuse inframe with GST (glutathione $S$-transferase) in the pGEX-2T vector (Pharmacia). Cultures containing the recombinant plasmids were grown aerobically in LB broth and expression from the T7 promoter was induced by addition of $1 \mathrm{mM}$ IPTG. $\mathrm{His}_{6}$-NifA fusion protein was purified by nickel affinity chromatography on Hi-trap chelating columns (Pharmacia) and GST-NifLc fusion protein was purified by batch elution from affinity glutathione-Sepharose 4B beads (Pharmacia) as recommended by the manufacturer. SDS-PAGE of protein samples was performed by standard methods (Sambrook \& Russell, 2001).

Analysis of protein complexes. The pull-down assay was performed according to the method of Hasan et al. (2004). Purified GST-NifLc (10 ng) was immobilized on glutathione-Sepharose 4B beads and washed thoroughly with wash buffer $(20 \mathrm{mM}$ Tris/HCl pH 7.5, 2 mM EDTA, $100 \mathrm{mM} \mathrm{NaCl}, 12 \mathrm{mM} \beta$-mercaptoethanol and $0 \cdot 1 \%$ Triton X-100). Immobilized GST-NifLc was then incubated with the purified $\mathrm{His}_{6}$-NifA for $1 \mathrm{~h}$ at $4{ }^{\circ} \mathrm{C}$. After washing, bound proteins were eluted in SDS-PAGE sample buffer and separated by $8 \%$ SDS-PAGE. Western blotting with anti-histidine or anti-GST antibodies (Invitrogen) was performed by standard methods (Sambrook \& Russell, 2001). 
Table 3. Interaction between NifL and NifA detected by the yeast two-hybrid system

\begin{tabular}{|lccc|}
\hline Plasmid combination & $\begin{array}{c}\text { Growth on } \\
\text { selective media }\end{array}$ & $\begin{array}{c}\boldsymbol{\beta} \text {-Galactosidase activity } \dagger \\
\text { (Miller units) }\end{array}$ & Interacting peptides \\
\hline pGAD-SIP and pGBDU-SNF I & ++++ & $57 \cdot 6 \pm 1 \cdot 5$ & Positive control \\
pGAD-C and pGBD-C $_{1}$ and & - & $2 \cdot 7 \pm 0 \cdot 3$ & Negative control \\
pGAD-nifA and pGBD-nifL & ++ & $23 \cdot 6 \pm 1 \cdot 1$ & NifL and NifA \\
pGAD-nifL and pGBD-nifA & ++ & $25 \cdot 3 \pm 2 \cdot 3$ & NifL and NifA \\
pGAD-nifA and pGBD-nifLn (N-terminal domain) & - & $4 \cdot 1 \pm 0 \cdot 3$ & None \\
pGAD-nifA and pGBD-nifLc (C-terminal domain) & ++ & $22 \cdot 9 \pm 1 \cdot 3$ & NifL C-terminal domain and NifA \\
pGAD-nifL and pGBD-nifAn (N-terminal domain) & - & $5 \cdot 3 \pm 0 \cdot 5$ & None \\
pGAD-nifL and pGBD-nifAm (central domain) & ++ & $18 \pm 2 \cdot 7$ & NifL and NifA central domain \\
pGAD-nifL and pGBD-nifAc (C-terminal domain) & - & $3 \cdot 15 \pm 0 \cdot 7$ & None \\
pGAD-nifLc (C-terminal domain) and & ++ & $12 \cdot 0 \pm 2 \cdot 4$ & NifL C-terminal domain and \\
pGBD-nifAm (central domain) & & $13 \cdot 1 \pm 1 \cdot 6$ & NifA central domain \\
pGAD-nifAm (central domain) and & ++ & & NifA central domain and NifL \\
pGBD-nifLc (C-terminal domain) & - & $4 \cdot 4 \pm 0 \cdot 4$ & N-terminal domain \\
pGAD-nifA and pGBDC & - & $3 \pm 0 \cdot 2$ & None \\
pGAD-nifL and pGBDC & & &
\end{tabular}

${ }^{\star}$ Growth was assayed on three different media: SD lacking Leu, Trp and His; SD lacking Leu, Trp and Ade; and SD lacking Leu, Trp, His and Ade and containing X-Gal. + indicates that growth was observed on all three media and that colonies were blue on the X-Gal plates; - indicates that growth was not observed on any of the three media tested.

$\dagger \beta$-Galactosidase activities are the means $\pm \mathrm{SD}$ of three determinations.

\section{RESULTS}

\section{Properties of a nifL mutant strain non-polar on nifA expression and effect of overexpression of NifA and NifL}

A nifA mutant, as well as a nifL mutant polar on nifA expression, was previously shown to be devoid of nitrogenase activity (Desnoues et al., 2003). To further investigate the role of NifL in the regulation of nif gene expression in P. stutzeri, we used strain 1507B, in which most of the nifL coding sequence (1506 bp ClaI fragment) was substituted by a KIXX cassette cloned in the same orientation as the nifA gene. The non-polar effect of the nifL mutation on nifA expression was first checked by RT-PCR. A nifA transcript was indeed detected, both in the wild-type and in the 1507B nifL mutant, while no nifA transcript was produced in the nifL polar mutant constructed for this work, 1507A (Fig. 1a). The lack of nifA transcript in the nifL mutant 1507A strongly suggested that, as in other nitrogen fixers containing a nifL gene, nifA and nifL were transcribed from the same promoter in strain A1501. In addition, in strain $1507 \mathrm{~B}$ the presence of nifA transcript was consistent with nifA transcription from the $\mathrm{km}$ promoter of the cassette.

The nifL non-polar mutant strain 1507B displayed residual nitrogenase activity, up to $30 \%$ of that of the wild-type strain (Fig. 1b). It was then possible to investigate the effect of the increased production of NifA and NifL on nitrogenase activity by complementation analysis with plasmids expressing nifA or nifL. Expression of nifA in pVA3 was monitored from the $\mathrm{km}$ promoter of the vector. Indeed, $\mathrm{pVA} 3$ restored $30 \%$ nitrogenase activity to the nifA- $k m$ mutant (1506) and $n i f L-k m$ polar (1507A) strains (Fig. 1b), but the complementation reached up to $60 \%$ when kanamycin was added to the culture medium (not shown). As expected, pVA1, in which nifA was cloned in the opposite orientation, did not affect nitrogen fixation (Fig. 1b). Plasmid pVA3 also increased nitrogenase activity of the wild-type and of the nifL non-polar mutant 1507B (Fig. 1b). In contrast, plasmid $\mathrm{pVL}$, which carries the nifL gene, decreased nitrogenase activity of the wild-type and of the nifL non-polar mutant (Fig. 1b). Thus, NifL negatively modulates NifA activity. This is consistent with a role for NifL as NifA antiactivator.

\section{Physical interaction between NifL and NifA in vivo}

Deduced translation products of A1501 NifA and Azotobacter NifA share $82 \%$ identity, suggesting that the domain structure of the P. stutzeri protein is very similar to that defined in Azotobacter NifA, and hence in other NifAs (Studholme \& Dixon, 2003). This enabled us to design appropriate oligonucletides that could amplify portions encoding the N-terminal (NifAn), central (NifAm) and Cterminal (NifAc) domains, respectively, as schematized in Fig. 2. The same was applied to NifL, which shared $72 \%$ identity with Azotobacter NifL. In that case, the nifL gene was divided into only two regions, encompassing the $\mathrm{N}$-terminal PAS (NifLn) and the C-terminal (NifLc) domains, respectively (Fig. 2). Each of the domains was cloned into the yeast pGAD vector, which carries the activating domain of the yeast GAL4 transcriptional activator and into the pGBD 
(a)

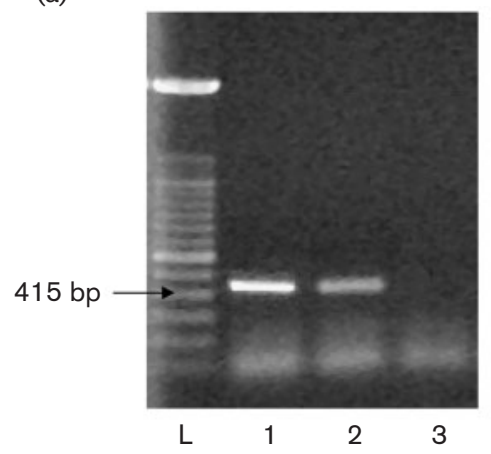

(b)

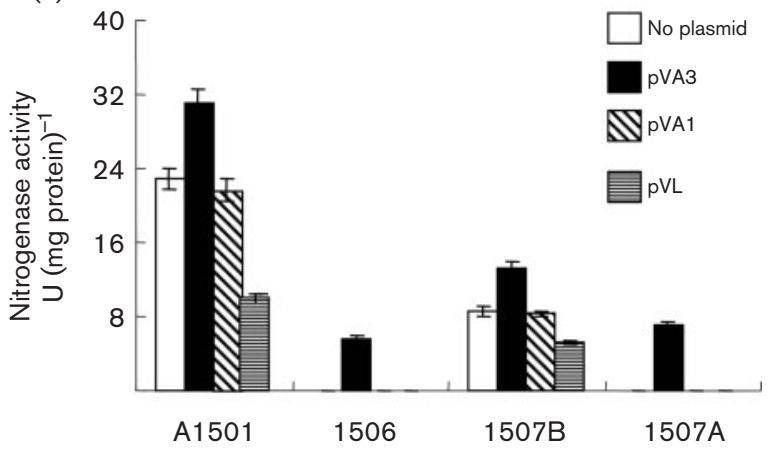

Fig. 1. Expression of nifA and nitrogenase activity in A1501 wild-type and mutant strains. (a) Amplification of nif $A$ transcript by RT-PCR. Lanes: L, DNA size marker; 1, wild-type; 2, 1507B non-polar nifL mutant; 3, 1507A nifL polar mutant. The arrow indicates the $415 \mathrm{bp}$ amplification product of nifA. (b) Nitrogenase activity in wild-type and mutant strains complemented with plasmids carrying nifA and nif $L$ and incubated under nitrogen-fixation conditions: A1501, wild-type; 1507B, nif $L-k m$ non-polar mutant; 1507A, nifL-km polar mutant; 1506, nifA-km mutant. pVA3 contains nifA under the control of the $\mathrm{km}$ promoter; pVA1 contains nifA in the opposite orientation; $\mathrm{pVL}$ contains nifL.

vector, which carries the DNA-binding domain of GAL4. After co-transformation into yeast strain PJ69-4A, an interaction between the peptides fused to the pGAD and pGBD vectors is required so that the transcription from the promoters under the control of GAL4 can proceed (Table 3 ). As one of the reporter genes is lac $Z$, an enzymic assay for $\beta$-galactosidase gives an estimation of the relative strength of the interaction (James et al., 1996). Fig. 3 shows an example of the growth on selective media and Table 3 summarizes the data obtained for growth and $\beta$-galactosidase activity. From these data it is concluded that an interaction is detected between the entire NifA and NifL,
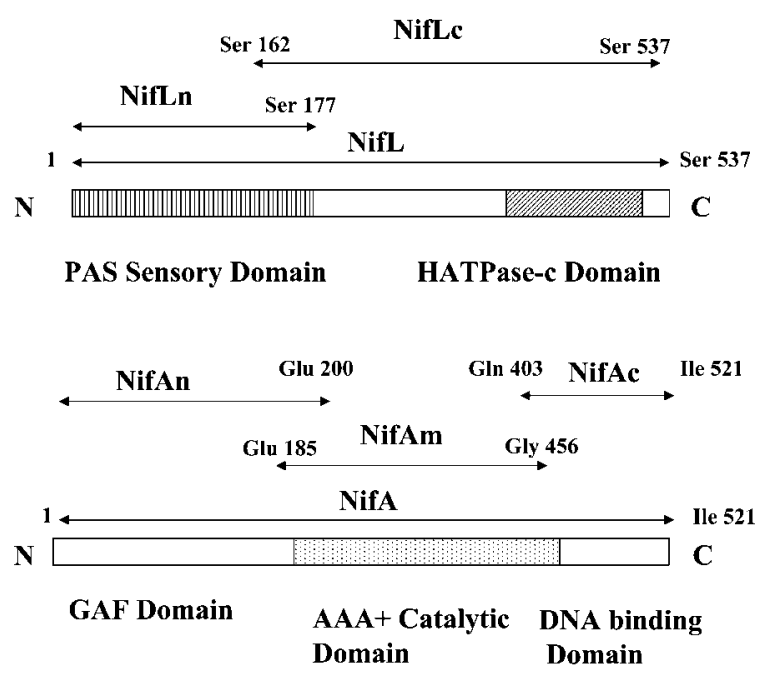

Fig. 2. Schematic representation of the domains of NifL (top) and NifA (bottom). See text for explanations. The oligonucleotides designed to amplify the gene portions encoding the different domains are listed in Table 3. and that the binding is limited to the C-terminal part of NifL and the central domain of NifA.

\section{Physical interaction between NifLc and NifA in vitro}

To further confirm the interaction between NifLc and NifA, the corresponding DNA fragments were cloned into

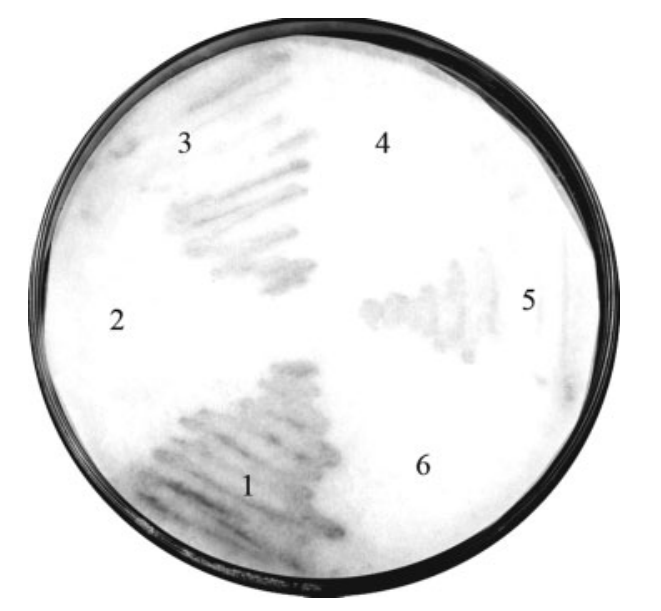

Fig. 3. Specificity of interaction between NifL and NifA. S. cerevisiae PJ69-4A strains carrying different plasmid combinations were grown on SD medium lacking Leu, Trp, His and Ade and containing $\mathrm{X}-\mathrm{Gal}$, and the colony filter-lift assay in the presence of $\mathrm{X}-\mathrm{Gal}$ was performed according to the protocol of the Matchmaker manual: 1, positive control; 2, pGAD-nifAc (Cterminal) + pGBD-nifL (entire nifL coding region); 3, pGAD-nifA (entire nifA coding region)+pGBD-nifL (entire nifL coding region); 4, pGBD-nifAn ( $\mathrm{N}$-terminal)+pGBD-nifL (entire nifL coding region); 5, pGBD-nifAm (central domain) + pGBD-nifLc (C-terminal); 6, negative control (pGAD-C1, pGBD-C1). 
expression vectors to obtain a GST-NifLc and a $\mathrm{His}_{6}-\mathrm{NifA}$ fusion protein as described in Methods. After purification and SDS-PAGE analysis, the GST-NifLc product had an apparent molecular mass in the range $67 \mathrm{kDa}$, consistent with the size of the NifL C-terminal part, $40.7 \mathrm{kDa}$ (from residues 162-537; Fig. 2), and the GST moiety of $27 \mathrm{kDa}$. The migration of the $\mathrm{His}_{6}$-NifA product, estimated at $64 \cdot 2 \mathrm{kDa}$, was similar to that of the GST-NifLc fusion (Fig. 4). However, the two fusion proteins could be easily differentiated using anti-histidine or anti-GST antibodies after Western blotting, as shown below.

The result of NifLA complex formation and elution using the pull-down assay is shown in Fig. 4. Lanes 1 and 3 correspond to control experiments performed only with NifA (lane 1) or with NifLc (lane 3), while lane 2 contained the elution product after the complex formation between NifLc and NifA. Fig. 4(a) shows protein staining. Anti-GST antibody, shown in Fig. 4(b), revealed material containing the GST-NifLc in lane 3 but not in lane 1, whereas anti-His antibody, in panel (c), revealed material containing $\mathrm{His}_{6}$ NifA in lane 1 but not in lane 3. Both antibodies revealed a protein product in lane 2 (Fig. $4 \mathrm{~b}, \mathrm{c}$ ), suggesting that it corresponded to a mixture of NifA and NifLc. This is strongly in favour of complex formation between NifL and NifA, suggesting a specific binding between NifA and NifLc.

\section{DISCUSSION}

It was previously established that a nifL mutant polar on nifA expression led to a Nif phenotype in P. stutzeri A1501 (Desnoues et al., 2003). In this report, assay for nitrogenase activity of the nifL non-polar mutant 1507B showed it displayed a significant residual activity, suggesting that NifL is not an essential product for nitrogen fixation in strain A1501. This result is similar to that reported first in the case of K. pneumoniae (see Filser et al., 1983) and subsequently found in other strains containing a nifL gene, such as Azotobacter vinelandii (Blanco et al., 1993) and Azoarcus sp. (Egener et al., 2002). In addition, the decrease of nitrogenase activity observed both in the wild-type and in the nifL nonpolar mutant in the presence of NifL excess produced by plasmid pVL (Fig. 1) is consistent with previous observations in K. pneumoniae (Buchanan-Wollaston et al., 1981). Thus, NifL most likely acts in modulating NifA activity in
A1501, and this suggests that NifL is an antiactivator of NifA activity.

The yeast two-hybrid system is a useful technique to detect protein-protein interaction (James et al., 1996). It has been successfully used to explore binding between several components of the ntr and nif regulatory systems (Lei et al., 1999; Martínez-Argudo et al., 2002; Rudnick et al., 2002; Pawlowski et al., 2003; Chen et al., 2005). Thus, a direct protein-protein binding was detected between NifA and NifL in K. pneumoniae, Azotobacter vinelandii and Enterobacter cloacae (Lei et al., 1999; Martínez-Argudo et al., 2002; Liao et al., 2002). Results reported in P. stutzeri reveal also a direct protein-protein interaction between NifA and NifL and more precisely between the NifL GHKL (NifLc) and NifA AAA + (NifAm) domains. Indeed, NifL PAS domain (NifLn) does not display binding activity to NifA (Table 3).

A prerequisite to further study of the mechanisms of interaction between NifL and NifA is to obtain the protein products in a soluble form (Lee et al., 1993). In this work we used convenient expression vectors to overproduce Histagged NifA and GST fusion to NifLc. This enabled a rapid purification of both proteins and allowed us to demonstrate in vitro complex formation between NifLc and NifA (Fig. 4). This is consistent with the in vivo binding observed. It also suggests that under conditions not compatible with nitrogen fixation, inactivation of NifA is probably due to a protein complex between NifL and NifA so that nif genes cannot be transcribed and hence nitrogenase cannot be synthesized.

Mechanisms by which NifL and NifA modulate nif gene expression have been mainly studied in K. pneumoniae and A. vinelandii. The activity of NifLA complexes is modulated by GlnK (a PII parologue protein), ATP/ADP ratio and 2oxoglutarate, but it is clear that mechanisms of signal communication between NifA and NifL are different in these two species (Martínez-Argudo et al., 2004). In both systems, GlnK, which senses the nitrogen status of the cell, was shown to interact with the NifLA via direct proteinprotein interaction (Stips et al., 2004; Martínez-Argudo et al., 2004). In the case of Azotobacter, when nitrogen is limiting, GlnK, in its uridylylated form, does not interact with NifL, and thus NifL does not antagonize NifA activity

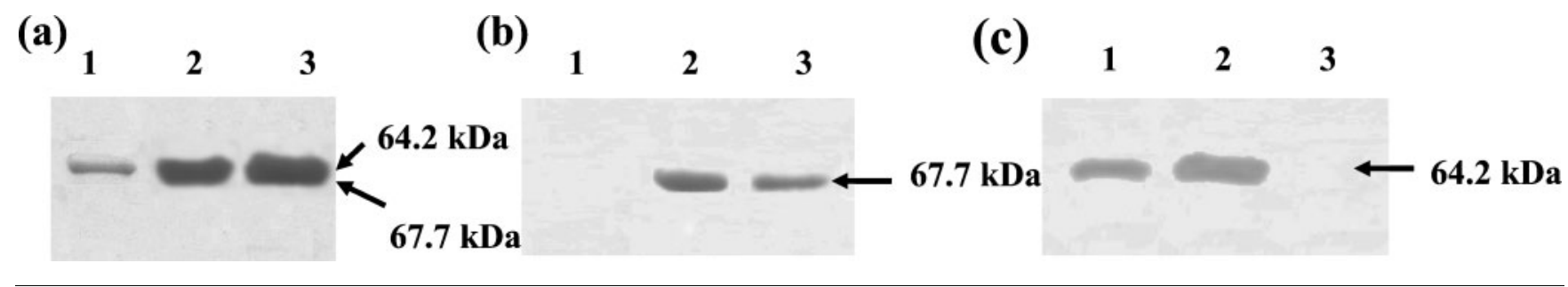

Fig. 4. Analysis of protein complexes after elution from the Sepharose column. (a) SDS-PAGE. (b) Western blot with GSTTag antibody. (c) Western blot with His-Tag antibody, Lanes: 1, control His 6 -NifA; 2, His ${ }_{6}-\mathrm{NifA}+\mathrm{GST}-\mathrm{NifLc}$; 3 , control GST-NifLc. 
(Martínez-Argudo et al., 2004). In contrast, GlnK is required for the relief of NifL inhibition in K. pneumoniae (He et al., 1998; Stips et al., 2004). In the present report, we have limited our investigation to the demonstration of an interaction between NifL and NifA, using both in vivo and in vitro techniques. It is not known whether a PII protein is involved in the modulation of NifLA activity. $P$. stutzeri A1501 carries a single copy of a $g \ln B$-like gene (this laboratory, unpublished observation), as in Azotobacter. The inactivation of the $g \ln B$-like gene and the purification of its protein product is in progress. Although $P$. stutzeri nifL is not an essential gene for nitrogen fixation, the NifL protein plays a regulatory role as antiactivator of NifA activity. The purification of both NifA and NifL proteins opens interesting perspectives to further study the mechanisms of interaction of NifL and NifA in this species.

\section{ACKNOWLEDGEMENTS}

The authors wish to thank Ms Nicole Desnoues for the construction of strain 1507B, Dr Sanfeng Chen for providing the plasmid vectors for the $\mathrm{Y} 2 \mathrm{H}$ experiments and Ms Patricia Shapiro for reading the typescript. This work was supported by funds from National Programs of China '973' (grant no. 2001CB108904) and '863' (grant no. 2001AA214021).

\section{REFERENCES}

Allen, L. N. \& Hanson, R. S. (1985). Construction of broad-hostrange cosmid cloning vectors: identification of genes necessary for growth of Methylobacterium organophilum on methanol. J Bacteriol 161, 955-962.

Blanco, G., Drummond, M., Woodley, P. \& Kennedy, C. (1993). Sequence and molecular analysis of the nifL gene of Azotobacter vinelandii. Mol Microbiol 9, 869-879.

Buchanan-Wollaston, V., Cannon, M. C. \& Cannon, F. C. (1981). The use of cloned nif (nitrogen fixation) DNA to investigate transcriptional regulation of nif expression in K. pneumoniae. Mol Gen Genet 184, 102-106.

Chan, Y. K., Barraquio, W. L. \& Knowles, R. (1994). $\mathrm{N}_{2}$-fixing Pseudomonas and related soil bacteria. FEMS Microbiol Rev 13, 95-117.

Chen, S., Liu, L., Zhou, X., Elmerich, C. \& Li, J.-L. (2005). Functional analysis of the GAF domain of NifA in Azospirillum brasilense: effects of Tyr-Phe mutations on NifA and its interaction with GlnB. Mol Genet Genomics 273, 415-422.

Desnoues, N., Lin, M., Guo, X., Ma, L., Carreño-Lopez, R. \& Elmerich, C. (2003). Nitrogen fixation genetics and regulation in a Pseudomonas stutzeri strain associated with rice. Microbiology 149, 2251-2262.

Egener, T., Sarkar, A., Martin, D. E. \& Reinhold-Hurek, B. (2002). Identification of a NifL-like protein in a diazotroph of the betasubgroup of the Proteobacteria, Azoarcus sp. strain BH72. Microbiology 148, 3203-3212.

Filser, M., Merrick, M. \& Cannon, F. (1983). Cloning and characterization of nifLA regulatory mutations from Klebsiella pneumoniae. Mol Gen Genet 191, 485-491.

Hasan, M. K., Yaguchi, T., Minoda, Y., Hirano, T., Taira, K., Wadhwa, R. \& Kaul, S. C. (2004). Alternative reading frame protein (ARF)independent function of CARF (collaborator of ARF) involves its interactions with p53: evidence for a novel p53-activation pathway and its negative feedback control. Biochem J 380, 605-610.

He, L., Soupène, E., Ninfa, A. \& Kustu, S. (1998). Physiological role for the GlnK protein of enteric bacteria: relief of NifL inhibition under nitrogen-limiting conditions. J Bacteriol 180, 6661-6667.

James, P., Halladay, J. \& Craig, E. A. (1996). Genomic libraries and a host strain designed for highly efficient two-hybrid selection in yeast. Genetics 144, 1425-1436.

Lalucat, J., Bennasar, A., Bosch, R., Garcia-Valdés, E. \& Palleroni, N. J. (2006). Biology of Pseudomonas stutzeri. Microbiol Mol Biol Rev 70, 510-547.

Lee, H. S., Berger, D. K. \& Kustu, S. (1993). Activity of purified NIFA, a transcriptional activator of nitrogen fixation genes. Proc Natl Acad Sci U S A 90, 2266-2270.

Lei, S., Pulakat, L. \& Gavini, N. (1999). Genetic analysis of nif regulatory genes by utilizing the yeast two-hybrid system detected formation of a NifL-NifA complex that is implicated in regulated expression of nif genes. J Bacteriol 181, 6535-6539.

Liao, G. X., Yu, G. Q. \& Shen, S. J. (2002). Use of bacterial two-hybrid system to investigate the molecular interaction between the regulators NifA and NifL of Enterobacter cloacae. Sci China C 45, 569-576.

Lin, M., Smalla, K., Heuer, H. \& van Elsas, J. D. (2000). Effect of an Alcaligenes faecalis inoculant strain on bacterial communities in flooded microcosms planted with rice seedlings. Appl Soil Ecol 15, 211-225.

Martínez-Argudo, I., Salinas, P., Maldonado, R. \& Contreras, A. (2002). Domain interactions on the $n t r$ signal transduction pathway: two-hybrid analysis of mutant and truncated derivatives of histidine kinase NtrB. J Bacteriol 184, 200-206.

Martínez-Argudo, I., Little, R., Shearer, N., Johnson, P. \& Dixon, R. (2004). The NifL-NifA system: a multidomain transcriptional regulatory complex that integrates environmental signals. $J$ Bacteriol 186, 601-610.

Merrick, M. J. (2004). Regulation of nitrogen fixation in free-living diazotrophs. In Genetics and Regulation of Nitrogen Fixation in FreeLiving Bacteria. Edited by W. Klipp, B. Masepohl, J. P. Gallon \& W. E. Newton. The Netherlands: Kluwer Academic.

Miller, J. (1972). Assay for $\beta$-galactosidase. In Experiments in Molecular Genetics, pp. 352-355. Cold Spring Harbor, NY: Cold Spring Harbor Laboratory.

Morett, E. \& Segovia, L. (1993). The $\sigma^{54}$ bacterial enhancer-binding protein family: mechanism of action and phylogenetic relationship of their functional domains. J Bacteriol 175, 6067-6074.

Pawlowski, A., Riedel, K. U., Klipp, W., Dreiskemper, P., Gross, S., Beirhoff, H., Drepper, T. \& Masepohl, B. (2003). Yeast two hybrid studies on interaction of proteins involved in regulation of nitrogen fixation in the phototrophic bacterium Rhodobacter capsulatus. J Bacteriol 185, 5240-5247.

Rediers, H., Vanderleyden, J. \& Mot, R. D. (2004). Azotobacter vinelandii: a Pseudomonas in disguise? Microbiology 150, 1117-1119.

Rudnick, P., Kunz, C., Gunatilaka, M. K., Hines, E. R. \& Kennedy, C. (2002). Role of GlnK in NifL-mediated regulation of NifA activity in Azotobacter vinelandii. J Bacteriol 184, 812-820.

Sambrook, J. \& Russell, D. W. (2001). Molecular Cloning: a Laboratory Manual, 3rd edn. Cold Spring Harbor, NY: Cold Spring Harbor Laboratory.

Simon, R., Priefer, U. \& Pühler, A. (1983). A broad host range mobilization system for in vivo genetic engineering: transposon mutagenesis in Gram-negative bacteria. Biotechnology 1, 784-791.

Stips, J., Thummer, R., Neumann, M. \& Schmitz, R. A. (2004). GlnK effects complex formation between NifA and NifL in Klebsiella pneumoniae. Eur J Biochem 271, 3379-3388. 
Studholme, D. \& Dixon, R. (2003). Domain architectures of $\sigma^{54}$ dependent transcriptional activators. J Bacteriol 185, 1757-1767.

Vermeiren, H., Willems, A., Schoofs, G., de Mot, R., Keijers, V., Hai, W. \& Vanderleyden, J. (1999). The rice inoculant strain A15 is a nitrogen-fixing Pseudomonas stutzeri strain. Syst Appl Microbiol 22, 215-224.
You, C. B., Song, H. X., Wang, J. P., Lin, M. \& Hai, W. L. (1991). Association of Alcaligenes faecalis with wetland rice. Plant Soil 137, 81-85.

Zhulin, I. B., Taylor, B. L. \& Dixon, R. (1997). PAS domain S-boxes in Archaea, Bacteria and sensors for oxygen and redox. Trends Biochem Sci 22, 331-333. 